\title{
Addition of meloxicam to the treatment of bovine clinical mastitis results in a net economic benefit to the dairy farmer
}

\author{
Felix J. S. van Soest, ${ }^{* 1}$ Elke Abbeloos, $†$ Scott McDougall, $\ddagger$ and Henk Hogeveen ${ }^{\star}$ \\ *Business Economics Group, Social Sciences, Wageningen University, Hollandseweg 1, 6706 KN Wageningen, the Netherlands \\ †Boehringer Ingelheim Animal Health GmbH, Binger Strasse 173, 55216 Ingelheim am Rhein, Germany \\ $¥$ Cognosco, AnexaFVC, Morrinsville 3300, New Zealand \\ §Department of Farm Animal Health, Faculty of Veterinary Medicine, Utrecht University, Yalelaan 7, $3584 \mathrm{CL}$, Utrecht, the Netherlands
}

\begin{abstract}
Recently, it has been shown that the addition of meloxicam to standard antimicrobial therapy for clinical mastitis (CM) improves the conception rate of dairy cows contracting $\mathrm{CM}$ in the first $120 \mathrm{~d}$ in milk. The objective of our study was to assess whether this improved reproduction through additional treatment with meloxicam would result in a positive net economic benefit for the farmer. We developed a stochastic bio-economic simulation model, in which a dairy cow with CM in the first $120 \mathrm{~d}$ in milk was simulated. Two scenarios were simulated in which $\mathrm{CM}$ cases were treated with meloxicam in conjunction with antimicrobial therapy or with antimicrobial therapy alone. The scenarios differed for conception rates (31\% with meloxicam or $21 \%$ without meloxicam) and for the cost of CM treatment. Sensitivity analyses were undertaken for the biological and economic components of the model to assess the effects of a wide range of inputs on inferences about the cost effectiveness of meloxicam treatment. Model results showed an average net economic benefit of $€ 42$ per CM case per year in favor of the meloxicam scenario. Cows in the no-meloxicam treatment scenario had higher returns on milk production, lower costs upon calving, and reduced costs of treatment. However, these did not outweigh the savings associated with lower feed intake, reduced number of inseminations, and the reduced culling rate. The net economic benefit favoring meloxicam therapy was a consequence of the better reproductive performance in the meloxicam scenario in which cows had a shorter calving to conception interval (132 vs. 143 d), a shorter intercalving interval (405 vs. $416 \mathrm{~d}$ ), and fewer inseminations per conception ( 2.9 vs. 3.7 ) compared with cows in the no-meloxicam
\end{abstract}

Received March 14, 2017.

Accepted September 9, 2017.

${ }^{1}$ Corresponding author: felix.vansoest@gmail.com treatment scenario. This resulted in a shorter lactation, hence a lower lactational milk production (8,441 vs. $8,517 \mathrm{~kg}$ per lactation) with lower feeding costs in the meloxicam group. A lower culling rate (12 vs. 25\%) resulted in lower replacement costs in the meloxicam treatment scenario. All of the scenarios evaluated in the sensitivity analyses favored meloxicam treatment over no meloxicam. This study demonstrated that improvements in conception rate achieved by the use of meloxicam, as additional therapy for mild to moderate $\mathrm{CM}$ in the first $120 \mathrm{~d}$ in milk, have positive economic benefits. This inference remained true over a wide range of technical and economic inputs, demonstrating that use of meloxicam is likely to be cost effective across many production systems.

Key words: bovine clinical mastitis, fertility, economics, animal health management

\section{INTRODUCTION}

Bovine clinical mastitis (CM) is a disease that has important consequences for farmers globally. Besides compromised cow welfare, it incurs economic losses through cost of treatment, production loss, and withdrawal of milk (Hogeveen et al., 2011). In addition, CM impairs reproductive performance, including a longer interval from calving to conception, more services per conception (Barker et al., 1998; Schrick et al., 2001), lower conception rates (Santos et al., 2004; Lavon et al., 2011), and a higher risk of embryo loss (Chebel et al., 2004; McDougall et al., 2005).

In a blinded, negative controlled, randomized intervention study carried out in 6 European countries, it was found that the addition of meloxicam, a nonsteroidal anti-inflammatory drug, to antimicrobial treatment of mild to moderate CM improved fertility in dairy cows (McDougall et al., 2016). Treatment with meloxicam was associated with a higher proportion of cows conceiving at their first AI (0.31 vs. 0.21$)$, and a higher proportion of meloxicam-treated cows becoming 
pregnant by $120 \mathrm{~d}$ after calving ( 0.40 vs. 0.31$)$. The number of AI required to achieve conception was lower in the meloxicam-treated cows compared with the control cows (2.43 vs. 2.92).

Fertility is an important factor in herd economics; we therefore hypothesized that improvements in fertility associated with treatment of mastitis with meloxicam would have an effect on profit. A stochastic calculation of the costs and benefits of treating mastitic cows with meloxicam would aid decision making at the individual cow level for a specific case of mastitis on a specific farm. Contrary to deterministic models that make definite predictions for quantities, a stochastic model, containing probability distributions, accounts for the uncertainty in the behavior of a system. This has the distinct advantage that individuals can be handled differently, whereby each simulation run contains animals with different performances in production and reproduction. Deterministic models do not account for such variation between individuals, which results in an oversimplification of the reality under which decisions need to be made (Dijkhuizen and Morris, 1997).

Previously developed stochastic models (Inchaisri et al., 2010; Rutten et al., 2014) have already assessed the economic consequences of reproductive performance in dairy cows. In those models, individual dairy cows were simulated in weekly time steps, in which all biologically relevant events occur: milk production, reproductive performance, feed intake, and herd removal. In these models, increased calving interval, involuntary culling, and the return of milk production were found to have the largest influence on the cost of reproductive efficiency. The objective of the current study was to assess whether the improved reproduction outcomes of treatment of CM with meloxicam would result in a positive net economic benefit for the farmer.

\section{MATERIALS AND METHODS}

\section{Model Specification}

We developed a stochastic dynamic simulation model to explore the economic consequences of improved reproductive performance in dairy cattle diagnosed with mild to moderate $\mathrm{CM}$ in the first $120 \mathrm{~d}$ in milk and treated with meloxicam in addition to antibiotic treatment. The basic properties of the model were copied from the model of Inchaisri et al. (2010), in which a dairy cow was simulated in weekly time steps during one randomly assigned parity. During each iteration, all biologically relevant events of a parity of a dairy cow were simulated from calving to either the next calving or culling. The biological events included the simulation of the reproductive cycle, milk production, and occurrence of CM. Occurrence of CM was specifically developed for the purpose of this study together with the effects of CM on the other biological events. First, the elements that have been copied from Inchaisri et al. (2010) will be briefly explained, and then we will explain in detail the specifics of CM occurrence and the effects on other biological events.

\section{Existing Model Specifications: Reproductive Cycle, Milk Yield, and Feed Intake}

The reproductive cycles included ovulation, estrus detection, insemination, conception, and calving. Ovulation was simulated from calving onward and followed a lognormal distribution. The ovulation interval was assumed to be at least 3 wk but could be delayed depending on the occurrence of postpartum disorders. The probability of estrus detection following ovulation was corrected for milk yield. Artificial insemination occurred when estrus was detected and the voluntary waiting period (VWP) was exceeded. The probability of conception in each iteration depended on the base conception risk (CR) of the scenario and was corrected for milk production level, parity, DIM, and occurrence of postpartum disorders other than CM. If insemination was unsuccessful, the process of ovulation, estrus detection, and AI continued. Some cows were considered to face embryonic death after an initial successful conception, which prolonged the reproductive cycle for a period of 6 to 8 wk before normal cyclicity resumed. The gestation length varied between 39 and $41 \mathrm{wk}$, following a uniform distribution. The week of drying off was fixed at wk 33 after successful conception, so that the dry period length (DPL) varied between 6 and 8 wk (Table 1). As a result of the stochastic simulation of the fertility events, each parity ends in week $n$, which is the length of the lactation plus DPL. For nonpregnant cows, logically, no dry period was required at the end of parity, and week $n$ was based on set culling rules. The culling rules were adapted from Rutten et al. (2014). Cows were eligible for herd removal when after 7 inseminations, either no successful insemination occurred or a cow did not have a successful conception at wk 42 after calving. Nonpregnant cows were removed when their daily milk yield dropped below $15 \mathrm{~kg}$ of milk/d. The length of parity for each iteration is thus variable and depends on pregnancy status.

The potential milk production of any given cow depended on the average herd milk production and was corrected for the individual cows' performance index during the lactation (a value from 0.9 to 1.1 drawn from a normal distribution), and parity (randomly drawn from the parity distribution). The potential milk production was used to determine the average daily milk 
yield per week $i\left(M Y_{i}\right)$, based on the Wood function (Wood, 1967). The weekly milk yield was corrected for conception status, occurrence of CM, and DIM. Milk production stopped at either the date of drying off or at the moment of culling.

The weekly feed requirements were estimated based on the weekly milk yield and expressed as the required energy in feed units for lactation (VEM) as defined by van Es (1978). One feed unit of VEM equals $1.65 \mathrm{kcal}$ of energy, and 1,000 VEM equals $1 \mathrm{kVEM}$. The weekly kVEM were influenced by milk production, pregnancy status, and dry period.

\section{Development of CM Model Additions and Adaptations to Existing Model}

Consistent with McDougall et al. (2016), cows in our model were considered to have an episode of mild to moderate mastitis within the first $120 \mathrm{~d}$ in milk. Mild to moderate cases were defined as cows diagnosed with apparent changes in the milk, local inflammation in the mammary gland, or both, but without systemic symptoms (Erskine et al., 2003). The existing models described above were adjusted such that all biologically relevant events associated with $\mathrm{CM}$ were included: the risk of conception, milk production loss, and discarded milk. Model input is presented in Table 1. Consequently, 2 treatment scenarios were simulated: a scenario in which meloxicam was used as additional treatment for $\mathrm{CM}$ and one in which no meloxicam was used. The tested scenarios are an economic continuation of the findings found by McDougall et al. (2016), in which meloxicam-treated cases of CM had a higher CR compared with no-meloxicam cases of CM (0.31 vs. 0.21). The model and simulations were developed and performed in Microsoft Excel (Microsoft Corp., Redmond, WA) using the @Risk add-in software (Palisade Corp., Ithaca, NY) for the stochastic properties of the model. For each analysis, 50,000 iterations were run. More indepth model specification regarding the components that have been developed previously can be found in Inchaisri et al. (2010) and Rutten et al. (2014). The adjustments and additions to the previous models are described in more detail in the following sections.

\section{Base Conception Risk}

The base CR was set at 0.21 for $\mathrm{CM}$ cases in the no-meloxicam scenario, and at 0.31 for $\mathrm{CM}$ cases in the meloxicam treatment scenario (McDougall et al., 2016). The probability of a successful conception gradually increased in weekly time steps.

Table 1. Description of input parameters, corresponding values, abbreviations, and reference sources

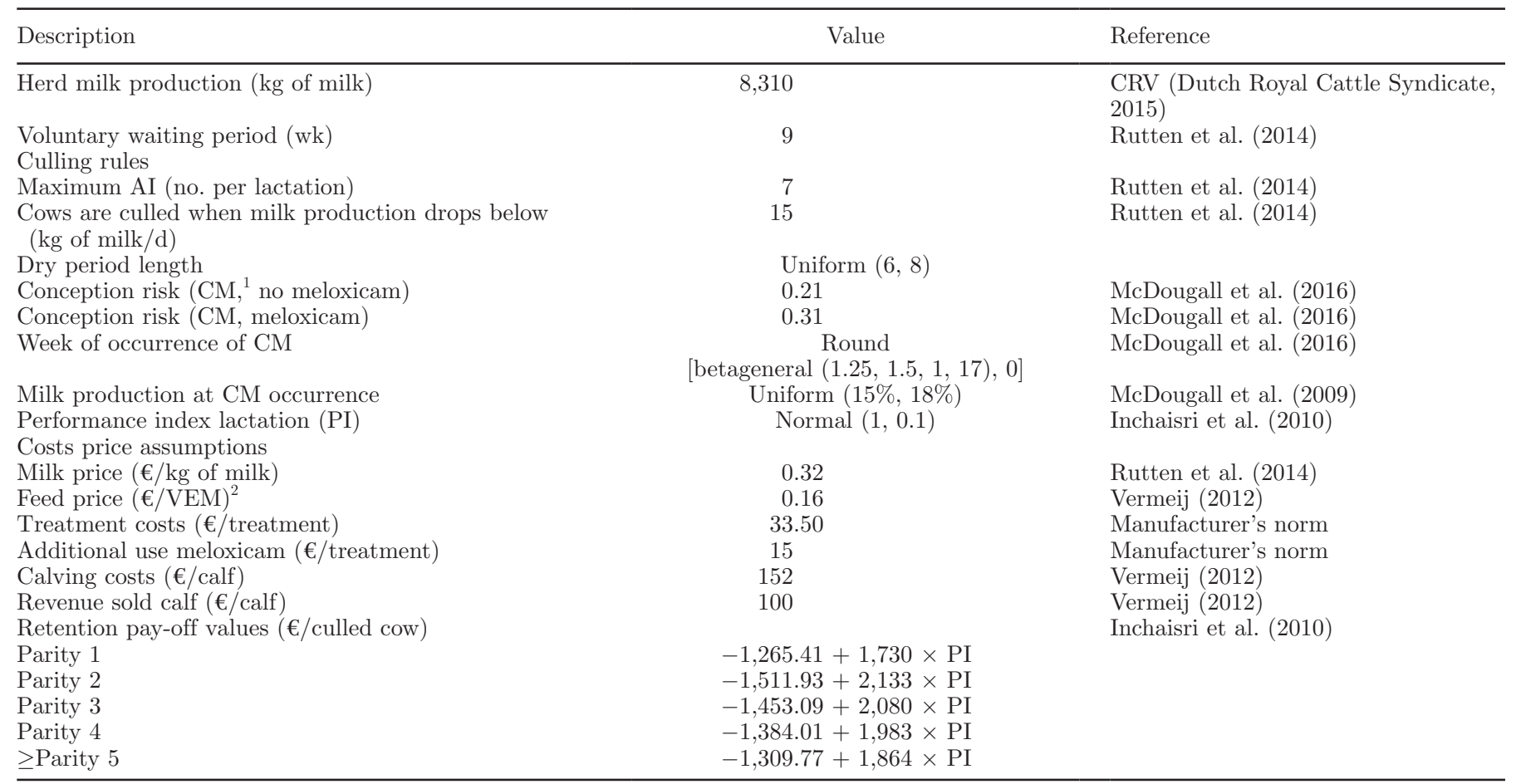

${ }^{1}$ Clinical mastitis.

${ }^{2}$ Feed requirements estimated as energy requirements in feed units for lactation (VEM; $1,000 \mathrm{VEM}=1 \mathrm{kVEM}=1,650 \mathrm{kcal}$ ) as defined by van Es (1978). 


\section{Clinical Mastitis}

For each lactation, the week in which CM occurred $\left(W I M^{C M}\right.$ ) was modeled following a $\beta$-distribution (Table 1) such that all cases occurred within the first $17 \mathrm{wk}$ of lactation (119 d) and the majority of cases occurred within the first weeks of lactation.

For each week $i$, the actual daily milk yield $\left(M Y_{i}^{a c t}\right)$ was based on the daily milk yield from the Wood function $\left(M Y_{i}\right)$ after correction for the occurrence of CM. The occurrence of CM was associated with an initial drop in daily milk yield commencing $1 \mathrm{wk}$ before the $W I M^{C M} ;\left(M Y_{i}^{a c t}\right)$ was estimated using equation [1]:

$$
M Y_{i}^{a c t}\left\{\begin{array}{c}
\text { if } i=W I M^{C M}-1 \rightarrow M Y_{i}-\left(M Y_{i} \times M P L^{\max } \times 0.75\right) \\
\text { if } i=W I M^{C M} \rightarrow M Y_{i}-\left(M Y_{i} \times M P L^{\max }\right) \\
\text { if } i>W I M^{C M} \text { and } M Y_{i-1}-M Y_{i-1}^{a c t}>0.015 \\
\quad \rightarrow M Y_{i}-\left[\left(M Y_{i-1}-M Y_{i-1}^{a c t}\right) \times 0.89\right] \\
\text { else } M Y_{i} \\
i=1, \ldots, n
\end{array}\right.
$$

In equation [1], production losses were associated with $\mathrm{CM}$ and expressed as a percentage of $M Y_{i}$. At $W I M^{C M}$, the production loss was at a maximum $\left(M P L^{\max }\right)$ and drawn from a uniform distribution (Table 1). The loss before $W I M^{C M}$ starts with $75 \%$ of the $M P L^{\max }$. In the weeks following $W I M^{C M}$, milk yield losses decreased gradually (McDougall et al., 2009) with $89 \%$ of the milk production loss in the preceding week. Once milk production loss in the preceding week was $<0.015 \mathrm{~kg}$ of milk/day, then $M Y_{i}^{\text {act }}$ was assumed to equal $M Y_{i}$.

In both treatments, CM was treated with antibiotic therapy; consequently, milk had to be discarded for a withdrawal period of $5 \mathrm{~d}$ immediately following treatment. The volume of the discarded milk $\left(M Y_{i}^{\text {disc }}\right)$ was estimated using equation [2]:

$$
M Y_{i}^{\text {disc }}\left\{\begin{array}{l}
\text { if } i=W I M^{C M} \rightarrow M Y_{i}^{a c t} \times 5 \\
\text { else } 0 \\
i=1, \ldots, n
\end{array}\right.
$$

In equation [2], $M Y_{i}^{\text {disc }}$ was estimated as the total amount of milk $(\mathrm{kg})$ discarded in week $i$. Milk withdrawal was assumed to occur at $W I M^{C M}$, and the amount of milk withdrawn was assumed to equal $M Y_{i}^{\text {act }}$ at $W I M^{C M}$ multiplied by the assumed withdrawal period.
For each iteration, the total amount of milk produced was summed $\left(M P^{\text {total }}\right) ; M P^{\text {total }}$ was simulated using equation [3]:

$$
M P^{\text {total }}=\left(\sum_{i}^{n} M Y_{i}^{a c t} \times 7-M Y_{i}^{\text {disc }}\right) .
$$

In equation [3], $M P^{\text {total }}$ is the total amount of $M Y_{i}^{\text {act }}$ minus $M Y_{i}^{\text {disc }}$ produced during one iteration.

\section{Economic Output}

For each iteration in both treatment scenarios, net cash flow (NCF) was estimated, resulting in 50,000 estimates of $\mathrm{NCF}$ for either treatment scenario. The net cash flow was estimated using equation [4] and was calculated based on costs and benefits associated with the technical parameters at the end of each iteration. These technical parameters included the total milk production during the lactation $\left(M P^{\text {total }}\right.$, expressed in $\mathrm{kg}$ of milk), the total feed intake (FI; expressed in kVEM), the total number of $\mathrm{AI}(A I)$, the final conception status $(S C O$; set to 1 after a successful conception, else assumed 0 ), and culling status (SCF; set to 1 after herd removal, else assumed 0). Both $S C O$ and $S C F$ were binary events, meaning that the event either occurred or did not occur; thus, costs only occurred once the event took place.

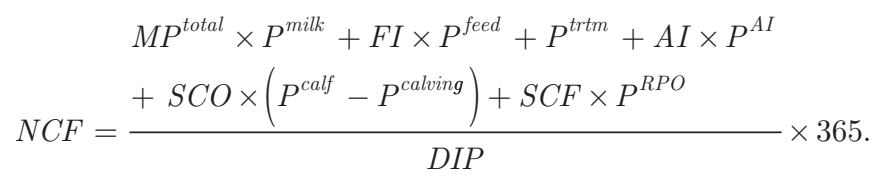

The numerator of equation [4] represents the cash flow for an individual dairy cow in her respective parity. Due to the stochasticity of the fertility events, each iteration results in a different parity length, expressed in days in parity $(\boldsymbol{D I P})$. Consequently, the numerator was divided by $D I P$ and multiplied by 365 to standardize results per cow per year and make the NCF comparable between and within treatment scenarios. Net cash flow included the following economic parameters: the price of milk $\left(P^{\text {milk }}\right)$, costs of feed $\left(P^{f e e d}\right)$, costs of treatment $\left(P^{t r t m}\right)$, costs of AI $\left(P^{A I}\right)$, calf price $\left(P^{\text {calf }}\right)$, calving management costs $\left(P^{\text {calving }}\right)$, and retention pay-off value depending on parity number $p\left(P^{R P O}\right)$; the assumed price levels are given in Table 1. The retention pay-off (RPO) values account for any future profit if the cow were kept until her optimal milk production compared with the immediate cost and benefit of replacing the animal 
(Dijkhuizen and Morris, 1997; Inchaisri et al., 2010). The majority of the price assumptions were similar to those of Inchaisri et al. (2010), with the exception of $P^{\text {milk }}$ and $P^{\text {feed }}$, which were based on Rutten et al. (2014) and assumed to be $€ 0.32 / \mathrm{kg}$ of milk and $€ 0.17 /$ $\mathrm{kVEM}$. Treatment costs of a case of CM were assumed at $€ 48.50$ for treatment with or $€ 33.50$ for treatment without meloxicam. The net economic benefit was the difference between the average NCF between the model scenarios without and with meloxicam.

\section{Sensitivity Analysis}

A technical sensitivity analysis was performed to represent a wide variety of management systems in Europe. Sensitivity of the model to the following parameters was tested: average milk production, estrus detection rate, production threshold at which nonpregnant cows are culled, VWP, average CR, and maximum number of AI per cow. Also, a change in percentage milk production loss due to CM was calculated in this technical analysis. An economic sensitivity analysis was performed to explore the net economic benefit in changing market situations: effect of milk price and feed cost, RPO, and cost of AI. The effect of milk price $(€ / \mathrm{kg}$ of milk) and feed costs $(€ / \mathrm{kVEM})$ were determined using the milk:feed price ratio (MFR). The MFR is the ratio between milk price and feed price. A high MFR thus represents a larger margin on the revenues compared with a situation with a low MFR. The MFR situations were based on the lowest and highest recorded longterm milk prices across the European Union (Eurostat, 2016). Three MFR values (1, 2, and 3) were used to determine the corresponding feed price and margin. Each of the MFR corresponded to a low milk price (MP) of $€ 0.15 / \mathrm{kg}$ of milk, medium MP of $€ 0.32 / \mathrm{kg}$ of milk, and high MP of $€ 0.47 / \mathrm{kg}$ of milk, resulting in a total of 9 potential MFR scenarios. For example, a medium MP and an MFR of 2 means that feed price equals $€ 0.16 /$ kVEM. Model validity was checked using the rationalism method and face validity (Sørensen, 1990).

\section{RESULTS}

\section{Technical Output}

Model results showed that the average milk yield per lactation (5th-95th percentile in parentheses) was estimated at $8,441(6,444-10,596) \mathrm{kg}$ of milk in the meloxicam treatment scenario versus $8,517(6,507-10,641) \mathrm{kg}$ of milk in the no-meloxicam scenario (Table 2). Reproductive performance was better in the meloxicam than in the no-meloxicam scenario. The average number of AI was $2.9(1-7)$ versus $3.6(1-7)$, calving to conception interval was 132 (56-252) d versus 143 (63-259) $\mathrm{d}$, and calving interval was $405(329-525) \mathrm{d}$ for the meloxicam treatment scenario versus 416 (336-532) d for the no-meloxicam treatment scenario. In both scenarios, $53 \%$ of all cows had a first AI within 3 wk after the VWP, and first service occurred, on average, 80 (56-126) d after calving. The percentage of dairy cows that were nonpregnant and therefore culled was $12 \%$ in the meloxicam scenario and $25 \%$ in the no-meloxicam scenario.

Discriminating technical output for pregnancy status showed that pregnant cows in the meloxicam scenario had a lower average milk production per lactation compared with pregnant cows in the no-meloxicam scenario: $8,443(6,426-10,622)$ versus $8,572(6,525-10,723) \mathrm{kg}$ of milk. The average calving interval in the meloxicam scenario was $405(329-528)$ d versus $416(336-532) \mathrm{d}$ in the no-meloxicam scenario. Conversely, nonpregnant

Table 2. Modeled mean (5th; 95th percentile in parentheses) of reproductive and productive outcomes per lactation for cows with clinical mastitis (CM) that were either treated with or without meloxicam in addition to routine antimicrobial therapy

\begin{tabular}{lcr}
\hline Item & Meloxicam & No meloxicam \\
\hline Number of AI per pregnant cow (no.) & $2.5(1 ; 6)$ & $2.9(1 ; 6)$ \\
Number of AI per cow (no.) & $2.9(1 ; 7)$ & $3.6(1 ; 7)$ \\
Calving to conception interval (d) & $132(56 ; 252)$ & $143(63 ; 259)$ \\
Calving to first service interval (d) & $80(56 ; 126)$ & $80(56 ; 126)$ \\
Calving interval (d) & $405(329 ; 525)$ & $416(336 ; 532)$ \\
Bred within 3 wk after VWP ${ }^{1}(\%)$ & 53 & 53 \\
Days in parity (d) & $396(315 ; 518)$ & $394(301 ; 525)$ \\
Milk production per cow per lactation (kg) & $8,441(6,444 ; 10,596)$ & $8,517(6,507 ; 10,641)$ \\
Feed intake per cow ( $\times 1,000 \mathrm{kVEM})^{2}$ & $620(497 ; 767)$ & $619(484 ; 772)$ \\
Cows culled for fertility reasons (\%) & 12 & 25 \\
${ }^{1}$ Voluntary waiting period. & & \\
${ }^{2}$ Feed requirements estimated as energy requirements in feed units for lactation (VEM; $1,000 \mathrm{VEM}=1 \mathrm{kVEM}$ \\
$=1,650$ kcal) as defined by van Es (1978).
\end{tabular}


cows in the meloxicam scenario had higher milk production than nonpregnant cows in the no-meloxicam scenario; 8,422 (6,557-10,421) versus 8,350 (6,470$10,402) \mathrm{kg}$ of milk (Table 3 ). Nonpregnant cows had a calving to culling interval of $328 \mathrm{~d}$ for both treatment scenarios. Nonpregnant cows received more AI during a lactation, $5.6(3-7)$ and $5.9(3-7)$ compared with pregnant cows, $2.5(1-6)$ and 2.9 (1-6), for the meloxicam and no-meloxicam scenarios, respectively.

\section{Economic Output}

The returns on sold milk were larger in the nomeloxicam scenario compared with the meloxicam treatment scenario: $€ 2,562$ compared with $€ 2,520 / \mathrm{CM}$ case per year. The largest cost factor was feed cost, which was slightly lower for the meloxicam treatment: $€ 931$ versus $€ 935 / \mathrm{CM}$ case per year. The average total feed intake in absolute levels per lactation was higher in the meloxicam treatment scenario (6,195 vs 6,190 $\times 1,000 \mathrm{kVEM})$; nevertheless, when economic results were standardized to euros per case of CM per year, the total costs of feed were lower (Table 4), which was due to the slightly longer length of lactation in the meloxicam treatment scenario (396 vs. 394 d). The largest cost differences between scenarios were found in AI (€80 vs. $€ 103$ per CM case per year) and culling costs for nonpregnant cows, both of which were lower in the meloxicam treatment scenario ( $€ 78$ vs. $€ 157$ per CM case per year). Both were a consequence of the better reproductive performance in the meloxicam treatment scenario, which resulted in less fertility-related culling. The NCF (5th-95th percentile in parentheses) for the meloxicam treatment scenario was $€ 1,343$ (€957$€ 1,796)$ and $€ 1,300$ (€947-€1,768)/CM case per year in the no-meloxicam treatment scenario. The average net economic benefit was thus $€ 42$ per $\mathrm{CM}$ case per year in favor of the meloxicam treatment scenario (difference due to rounding; Table 4). The cumulative density distribution presented in Figure 1 showed that NCF had a normal distribution for both treatment scenarios and overall better performance for meloxicam-treated cases of CM.

Discriminating economic output for pregnancy status shows that NCF (5th-95th percentile in parentheses) was higher for the pregnant cows in the meloxicam scenario: $€ 1,376$ (€973-€1,811) versus €1,364 (€963-€1,802) per $\mathrm{CM}$ case per year in the no-meloxicam scenario. The difference between nonpregnant cows in both scenarios was small: $€ 1,101$ (€930-€1,289) in the meloxicam treatment scenario and €1,106 (€937-€1,300) per CM case per year in the no-meloxicam treatment scenario (Table 5).

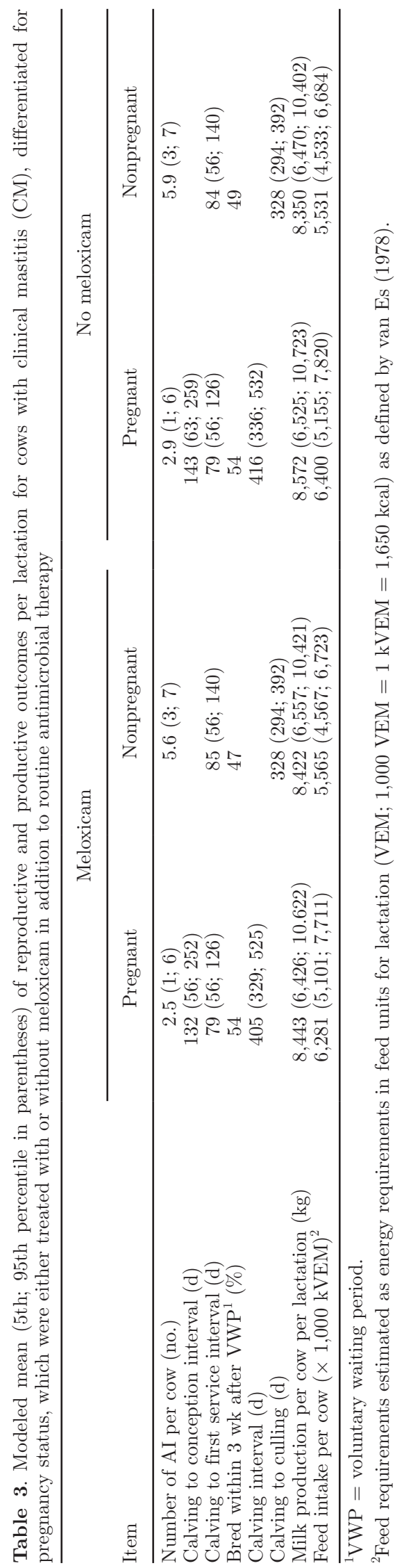


Table 4. Economic results presented as the different cost factors and net cash flow ${ }^{1}$ for an average case of clinical mastitis $(\mathrm{CM})$ with or without an additional treatment with meloxicam (5th; 95th percentile in parentheses)

\begin{tabular}{lccr}
\hline Item & \multicolumn{1}{c}{ Meloxicam } & No meloxicam & $\begin{array}{c}\text { Net economic } \\
\text { benefit }\end{array}$ \\
\hline Milk production & $2,520(1,967 ; 3,194)$ & $2,562(1,965 ; 3,294)$ & -42 \\
Feed intake & $-931(-1,067 ;-812)$ & $-935(-1,075 ;-810)$ & 3 \\
AI & $-80(-207 ;-29)$ & $-103(-243 ;-30)$ & 24 \\
Calving & $-42(-58 ; 0)$ & $-35(-56 ; 0)$ & -7 \\
CM treatment & $-46(-56 ;-34)$ & $-32(-41 ;-23)$ & -14 \\
Replacement & $-78(-699 ; 0)$ & $-157(-824 ; 0)$ & 49 \\
Net cash flow & $1,343(957 ; 1,756)$ & $1,300(947 ; 1,768)$ & 42 \\
\hline
\end{tabular}

${ }^{1}$ Values are presented in a standardized $€ / \mathrm{CM}$ case per year to make results comparable. The net economic benefit is the difference between meloxicam-treated cases and no-meloxicam cases. Any differences in net cash flow are due to rounding.

\section{Sensitivity Analysis}

Model results of the technical sensitivity analysis are presented in Figure 2 and those of the economic sensitivity analysis are presented in Figure 3. Results are presented as net economic benefit and the base result, $€ 42 / \mathrm{CM}$ case per year, was set as the reference line.

Technical Sensitivity Analysis. Results of the technical sensitivity analysis showed that all scenarios favored the meloxicam treatment scenario. The NCF was always largest for the meloxicam treatment scenario compared with the no-meloxicam scenario, resulting in a positive net economic benefit. A relatively low milk production per cow $(6,000 \mathrm{~kg}$ of milk/305 d) and increased waiting time to cull nonpregnant cows (milk production at culling $10 \mathrm{~kg}$ of milk/d) increased net economic benefit substantially: €59 and €54/CM case per year, respectively. An average estrus detection rate

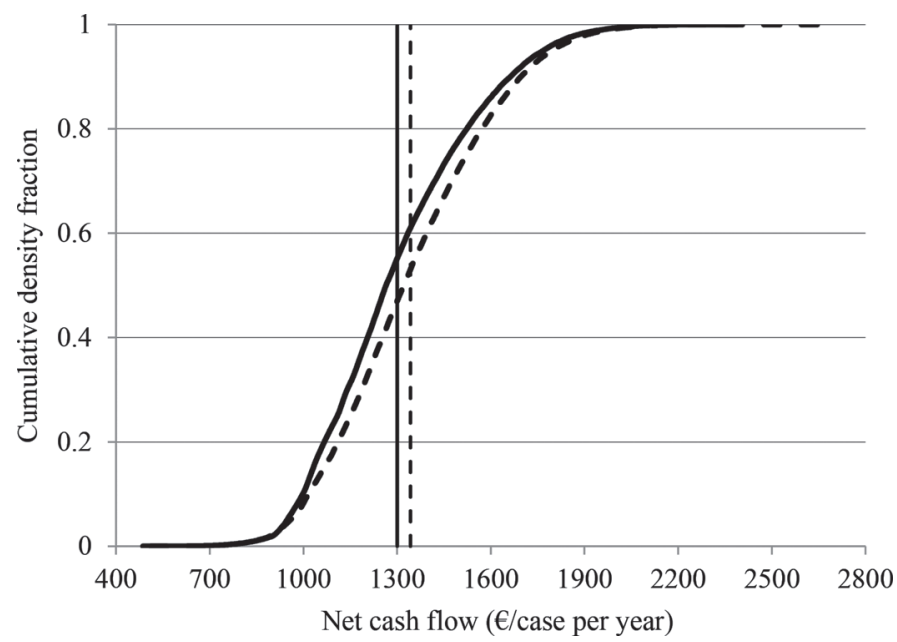

Figure 1. Cumulative density distribution of net cash flow for the meloxicam (dotted line) and no-meloxicam (solid line) treatment scenario; vertical lines represent the average values for both treatment scenarios. of $30 \%$ (base model 50\%) and reduced CR (CR 0.15 with and 0.1 without meloxicam treatment) decreased the net economic benefit to $€ 31$ and $€ 32 / \mathrm{CM}$ case per year, respectively. Increasing the VWP from 9 to 15 wk resulted in a net economic benefit of $€ 32 / \mathrm{CM}$ case per year.

Economic Sensitivity Analysis. Similar to the technical sensitivity analysis, model results on net economic benefit favored the meloxicam treatment scenario in all economic sensitivity analysis scenarios. A decreasing milk price, increasing AI costs, or increasing $\mathrm{RPO}$ value increased net economic benefit in favor of the meloxicam treatment scenario. An increasing milk price, lower AI costs, or reduced RPO value decreased net economic benefit. A high milk price in combination with an MFR of 3 resulted in a net economic benefit of $€ 18 / \mathrm{CM}$ case per year, which was the lowest average net economic benefit obtained in the sensitivity analysis. A scenario with a low milk price favors the meloxicam treatment scenario more than in the base scenario, with net economic benefits of $€ 66$ with an MFR of 3, $€ 64$ with an MFR of 2 , and $€ 63$ with a MFR 1 .

\section{DISCUSSION}

In this study, the standard treatment of mild to moderate $\mathrm{CM}$ in the first $120 \mathrm{~d}$ in milk was modeled with or without the additional benefit of meloxicam. Differences between treatments were based upon information derived from literature. Additional treatment with meloxicam of mild to moderate $\mathrm{CM}$ was found to increase CR from 0.21 to 0.31 and improve bacteriological cure rate (McDougall et al., 2016). In our study, only the change in CR was taken into account. McDougall et al. (2016) found no effects of an improved bacteriological cure rate on dairy cows' milk yield; hence, any further assumptions, such as the effect on milk production losses after meloxicam treatment, would have been speculative. We decided, therefore, to 
Table 5. Economic results differentiated for pregnancy status and presented as the different cost factors and net cash flow ${ }^{1}$ for an average case of clinical mastitis (CM) with or without an additional treatment with meloxicam (5th; 95th percentile in parentheses)

\begin{tabular}{lcrr}
\hline Item & Meloxicam & No meloxicam & $\begin{array}{c}\text { Net economic } \\
\text { benefit }\end{array}$ \\
\hline $\begin{array}{l}\text { Pregnant } \\
\text { Milk production }\end{array}$ & $2,455(1,952 ; 3,005)$ & $2,427(1,929 ; 2,977)$ & 27 \\
Feed intake & $-922(-1,047 ;-808)$ & $-915(-1,040 ;-801)$ & -7 \\
AI & $-65(-127 ;-29)$ & $-73(-137 ;-30)$ & 8 \\
Calves & $-48(-58 ;-36)$ & $-47(-56 ;-36)$ & -1 \\
CM treatment & $-45(-54 ;-34)$ & $-30(-36 ;-23)$ & -15 \\
Net cash flow & $1,376(973 ; 1,811)$ & $1,364(963 ; 1,802)$ & 12 \\
Nonpregnant & $2,997(2,447 ; 3,507)$ & $2,976(2,432 ; 3,496)$ & 21 \\
Milk production & $-1,001(-1,115 ;-886)$ & $-997(-1,112 ;-882)$ & -5 \\
Feed intake & $-188(-261 ;-100)$ & $-198(-261 ;-109)$ & 9 \\
AI & $-54(-60 ;-45)$ & $-38(-42 ;-31)$ & -17 \\
CM treatment & $-652(-1,000 ;-325)$ & $-638(-984 ;-299)$ & -14 \\
Nonpregnant cows & $1,101(930 ; 1,289)$ & $1,106(937 ; 1,300)$ & -5 \\
Net cash flow & &
\end{tabular}

${ }^{1}$ Values are presented in a standardized $€ / \mathrm{CM}$ case per year to make results comparable. The net economic benefit is the difference between meloxicam-treated cases and no-meloxicam cases. Any differences in net cash flow are due to rounding.

model conservatively and to simulate solely the positive effect of meloxicam on $\mathrm{CR}$ in cases of mild to moderate $\mathrm{CM}$ in the first $120 \mathrm{~d}$ in milk. Any additional positive effects of meloxicam treatment on bacteriological cure rate, improvements in subsequent SCC levels, or reduced milk production losses would only further favor the economic outcome toward the meloxicam treatment scenario.

The difference in $\mathrm{CR}$ between treatment scenarios resulted in 2 main reductions - the proportion of cows

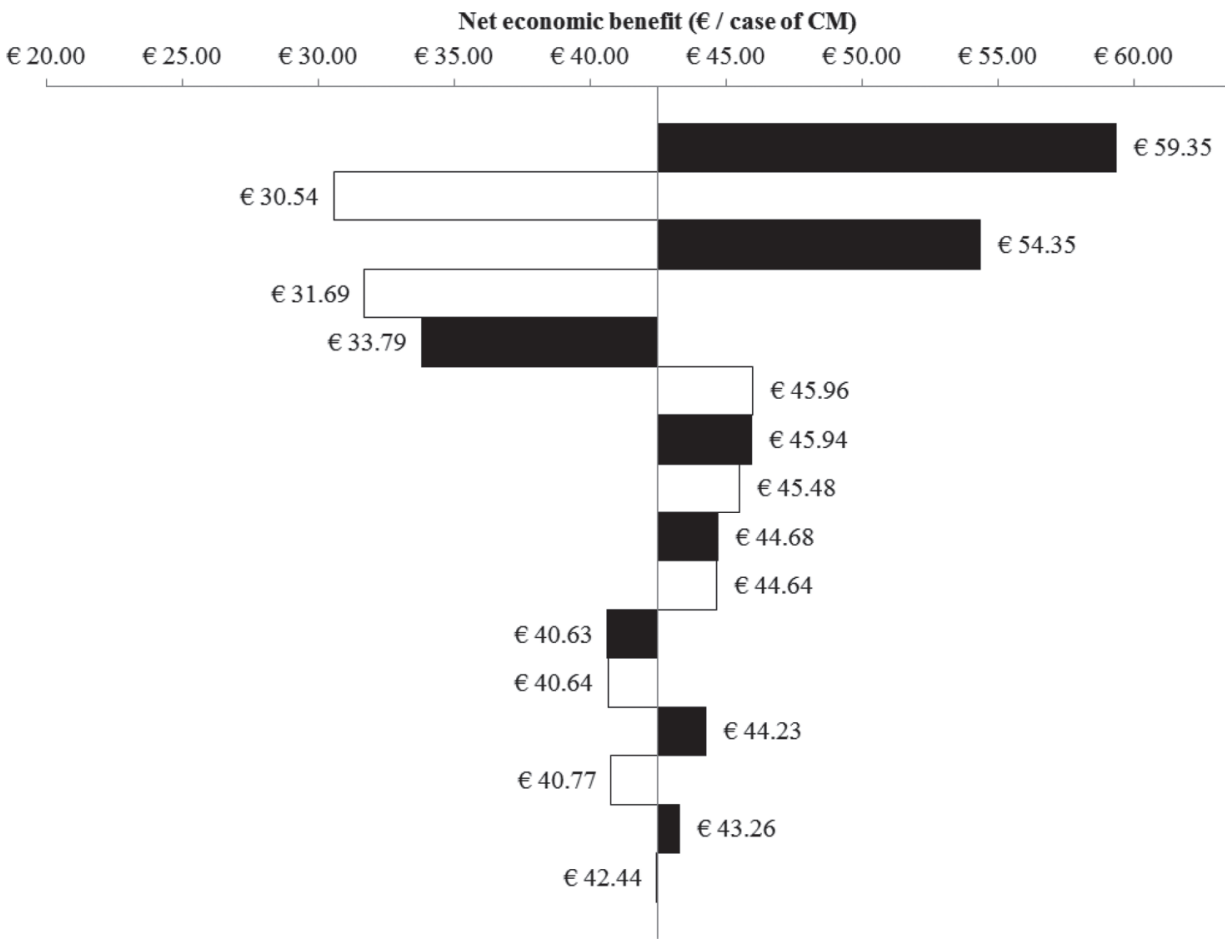

- Low milk production (herd avg 6,000 kg)

$\square$ Estrus detection rate $30 \%$

Milk production at culling $10 \mathrm{~kg}$ milk/d

$\square \mathrm{CR}$ with meloxicam 0.15 / without meloxicam 0.1

-VWP 15 wk

$\square$ Milk production at culling $20 \mathrm{~kg}$ milk/d

- Milk production loss CM (avg 21\%)

$\square$ VWP 6 wk

Milk production at culling $25 \mathrm{~kg}$ milk/d

$\square$ Estrus detection rate $70 \%$

-VWP 12 wk

$\square$ Max number of AI 6

- Max number of AI 8

$\square$ High milk production (herd avg 10,000 kg)

ه CR with meloxicam 0.4 / without meloxicam 0.27

$\square$ Milk production loss CM (avg 12\%)

Figure 2. Tornado graph of the net economic benefit of meloxicam treatment versus no meloxicam treatment (€/case of clinical mastitis, $\mathrm{CM}$ ) when the values of the single technical input parameters - estrus detection, conception rate (CR), voluntary waiting period (VWP), milk production loss associated with a case of $\mathrm{CM}$ at the moment of acquiring mild CM, maximum number of AI for each cow per parity, and the moment a cow is removed (due to nonpregnancy) from the herd once milk production drops below a certain threshold - were changed in both scenarios. 


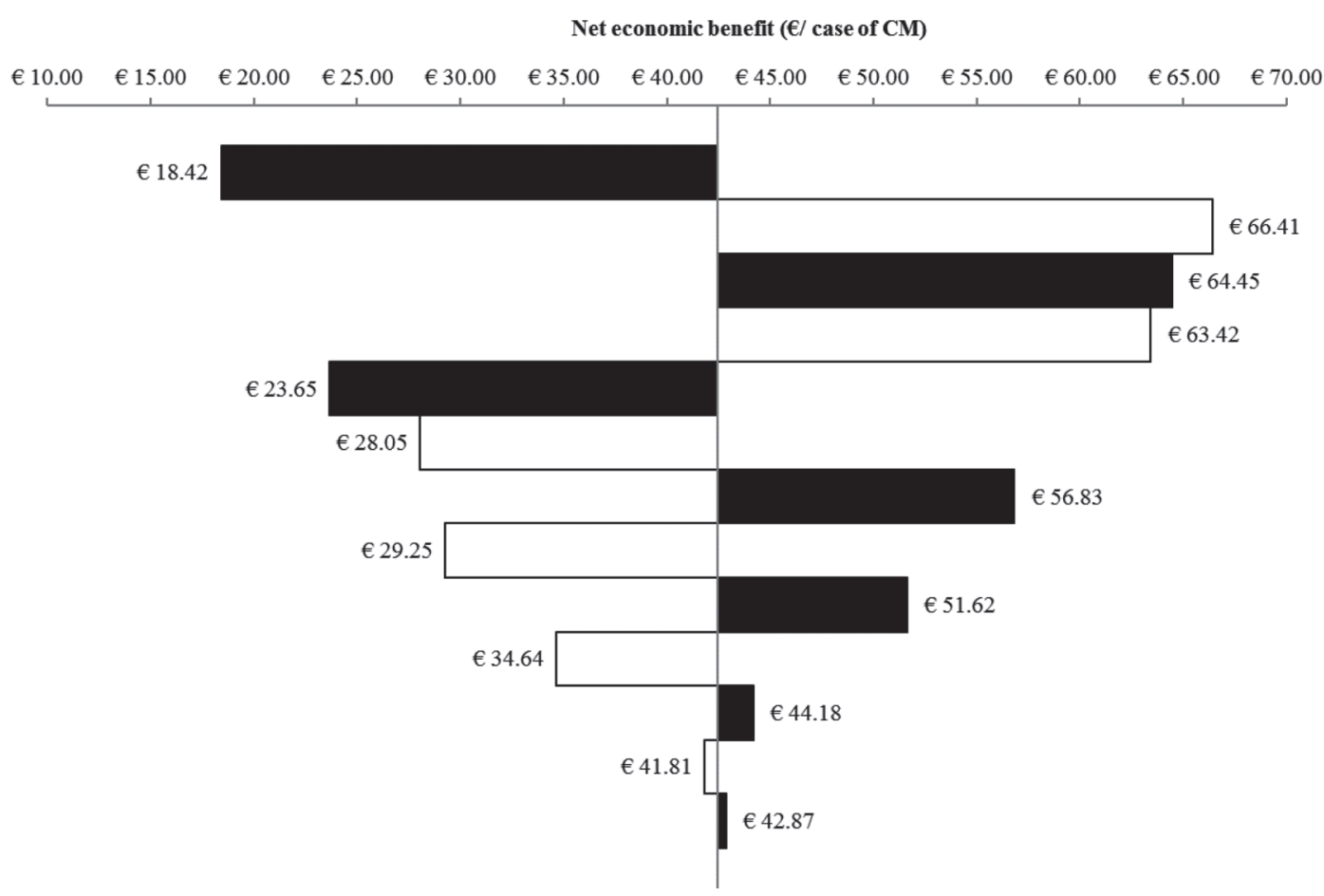

-High MP / high margin / MFR = 3 口Low MP $/$ low margin $/ \mathrm{MFR}=1$

- Low MP / high margin / MFR = 3

口Low MP / base margin / MFR $=2$

-High MP / base margin / MFR = 2

口RPV -€100

RPV $+€ 100$

口High MP / low margin / MFR = 1

-Price every insemination $€ 40$

口Price every insemination $€ 20$

- Base MP / low margin / MFR = 1

口Base MP / high margin / MFR = 3

- Price 1 st ins. $€ 45$, cons. prices $€ 30$

Figure 3. Tornado graph of the net economic benefit of meloxicam treatment versus no meloxicam treatment $(€ /$ case of clinical mastitis, $\mathrm{CM}$ ) when the values of the single economic parameters - milk price (MP); margin; milk and feed price ratio (MFR) in which a high MP is set at $€ 0.47$, medium MP is set at $€ 0.32$, and low MP is set at $€ 0.15$ per $\mathrm{kg}$ of milk; retention pay-off value (RPV); and insemination costs were changed in both scenarios, in which price of each first insemination was $€ 45$ and any consecutive inseminations were $€ 30$ per insemination.

culled for fertility reasons and the calving intervalboth in favor of the meloxicam treatment scenario. Of those 2 effects, culling was found to have the highest economic impact on the net economic benefit, increasing $\mathrm{NCF}$ by, on average, $€ 79$ per $\mathrm{CM}$ case per year in the no-meloxicam treatment scenario compared with the meloxicam treatment scenario. Culling percentages were $12 \%$ in the meloxicam treatment scenario and $25 \%$ in the no-meloxicam treatment scenario. Such culling rates may seem substantial and suggest a profound effect on the overall herd's replacement rate. It should be considered, however, that this concerns only cows with CM in the first $120 \mathrm{~d}$ in milk. This may, on an average 100-cow dairy farm, result in an average advantageous decrease of 1 to 2 removed animals for fertility reasons per year (Zwald et al., 2004; Lam et al., 2013). We modeled culling only due to fertility reasons, and culling rules were strictly the same for every cow. In practice, culling rules are also applied, albeit often in a less strict form where farmers might, for example, allow an extra insemination for a high-yielding dairy cow and vice versa. Nevertheless, relaxing the culling rules, either increasing or reducing the amount of allowed inseminations, did not reveal any major changes to the net economic benefit ( $€ 44$ vs. $€ 41$ per case of
CM per year, respectively). Although not a simulation target in this study, it should be recognized that in a previous study performed in New Zealand, with similar treatment scenarios to those in our study, very similar differences in culling rate were observed: $16 \%$ in the meloxicam scenario and $28 \%$ in the no-meloxicam scenario (McDougall et al., 2009).

The calving interval in the pregnant group averaged $405 \mathrm{~d}$ in the meloxicam treatment scenario and $416 \mathrm{~d}$ in the no-meloxicam treatment scenario. Perhaps counterintuitively, returns on milk production were found to be higher in the no-meloxicam treatment scenario, $€ 2,562$ per $\mathrm{CM}$ case per year, than in the meloxicam treatment scenario, $€ 2,520$ per CM case per year. This is because the no-meloxicam scenario had a higher proportion of nonpregnant cows (25 vs. $12 \%$ ), which showed higher returns on milk over pregnant cows in both treatment scenarios. The higher returns on milk production for nonpregnant cows can be explained as these cows remain in production until culled, on average $382 \mathrm{~d}$ for both treatment scenarios, whereas the calving interval of the pregnant cows includes a 6 - to 8-wk dry period. Nevertheless, an economic trade-off exists between culling and milk production. Our study showed, however, that the benefits of higher returns on 
milk production, favoring the no-meloxicam treatment scenario, are cancelled out by the associated increased culling costs.

The costs associated with CM have been estimated in previous studies; however, this is the first study to explore the costs of CM in relation to an improved CR. Therefore, and given the specific scenario simulated in this study, direct comparison with other economic studies is not possible. Costs of mastitis are traditionally compared with healthy individuals, which was not an aim of our study. In this study, we were interested in the economic difference between 2 treatment scenarios, which required a standardization of the results to cost per case of CM per year to make results comparable. The variation in NCF found between treatment scenarios is substantial and, to benefit economically the most from the meloxicam treatment, it is imperative that farmers treat all cases of mild to moderate CM with both antimicrobial therapy and meloxicam. The additional cost of meloxicam treatment was, on average, $€ 15$, which means a mean return on investment of 2.8. Considering the overall cash flow on a dairy farm, the average net economic benefit of $€ 42$ per CM case per year favoring the meloxicam treatment scenario, is relatively small. Therefore, economic argumentation may not persuade all farmers to change current $\mathrm{CM}$ treatment practice. Farmers value animal health and welfare next to economic losses and job satisfaction as important components in changing their mastitis management (Valeeva et al., 2007). Social norms and recognition for good stockmanship are also drivers for choice of treatment (Swinkels et al., 2015). Cows with CM are in pain (Fogsgaard et al., 2015) and treatment with meloxicam reduces pain (Fitzpatrick et al., 2013). In the case of lameness, it was found that a main motivator for farmers was pride in a healthy herd to reduce lameness incidence (Leach et al., 2010). An economic argument alone is unlikely to be effective in changing treatment behavior. Nevertheless, economic argumentation combined with the additional effects on a healthier herd status and welfare perspectives may lead to behavioral change. The addition of meloxicam to standard antibiotic mastitis therapy should, therefore, be seen mainly as an animal welfare-promoting measure with economic beneficial effects.

\section{CONCLUSIONS}

This study demonstrated that improvements in conception rate achieved by use of meloxicam, as additional therapy of mild to moderate CM in the first $120 \mathrm{~d}$ in milk, also have positive economic benefits. This inference remained true over a wide range of technical and economic inputs, demonstrating that use of meloxicam is likely to be cost effective across many production systems.

\section{ACKNOWLEDGMENTS}

This work was sponsored by Boehringer Ingelheim Animal Health GmbH (Ingelheim, Germany).

\section{REFERENCES}

Barker, A. R., F. N. Schrick, M. J. Lewis, H. H. Dowlen, and S. P. Oliver. 1998. Influence of clinical mastitis during early lactation on reproductive performance of Jersey cows. J. Dairy Sci. 81:1285-1290. https://doi.org/10.3168/jds.S0022-0302(98)75690-5.

Chebel, R. C., J. E. P. Santos, J. P. Reynolds, R. L. A. Cerri, S. O. Juchem, and M. Overton. 2004. Factors affecting conception rate after artificial insemination and pregnancy loss in lactating dairy cows. Anim. Reprod. Sci. 84:239-255. https://doi.org/10.1016/j .anireprosci.2003.12.012.

CRV (Dutch Royal Cattle Syndicate). 2015. Year Statistics. Accessed Jun. 11, 2016. https://www.crv4all.nl/wp-content/uploads/2016/ 02/Jaarstatistieken-2015-Nederland.pdf.

Dijkhuizen, A. A., and R. S. Morris. 1997. Animal health economics: Principles and applications. Pages 25-39 Chapter 3 Basic methods of economic analysis. R. B. M. Huirne and A. A. Dijkhuizen, ed. University of Sydney, Post-Graduate Foundation in Veterinary Science, Sydney, Australia.

Erskine, R. J., S. Wagner, and F. J. DeGraves. 2003. Mastitis therapy and pharmacology. Vet. Clin. North Am. Food Anim. Pract. 19:109-138. (vi.).

Eurostat. 2016. Selling prices of raw cow's milk. Accessed Oct. 17, 2016. http://ec.europa.eu/eurostat/tgm/table.do?tab=table\& plugin $=1 \&$ language $=$ en $\&$ pcode $=\operatorname{tag} 00070$.

Fitzpatrick, C. E., N. Chapinal, C. S. Petersson-Wolfe, T. J. DeVries, D. F. Kelton, T. F. Duffield, and K. E. Leslie. 2013. The effect of meloxicam on pain sensitivity, rumination time, and clinical signs in dairy cows with endotoxin-induced clinical mastitis. J. Dairy Sci. 96:2847-2856. https://doi.org/10.3168/jds.2012-5855.

Fogsgaard, K. K., T. W. Bennedsgaard, and M. S. Herskin. 2015. Behavioral changes in freestall-housed dairy cows with naturally occurring clinical mastitis. J. Dairy Sci. 98:1730-1738. https://doi .org/10.3168/jds.2014-8347.

Hogeveen, H., K. Huijps, and T. J. G. M. Lam. 2011. Economic aspects of mastitis: New developments. N. Z. Vet. J. 59:16-23. https://doi .org $/ 10.1080 / 00480169.2011 .547165$.

Inchaisri, C., R. Jorritsma, P. L. A. M. Vos, G. C. van der Weijden, and H. Hogeveen. 2010. Economic consequences of reproductive performance in dairy cattle. Theriogenology 74:835-846. https:// doi.org/10.1016/j.theriogenology.2010.04.008.

Lam, T. J. G. M., B. H. P. van den Borne, J. Jansen, K. Huijps, J. C. L. van Veersen, G. van Schaik, and H. Hogeveen. 2013. Improving bovine udder health: A national mastitis control program in the Netherlands. J. Dairy Sci. 96:1301-1311. https://doi.org/10.3168/ jds.2012-5958.

Lavon, Y., E. Ezra, G. Leitner, and D. Wolfenson. 2011. Association of conception rate with pattern and level of somatic cell count elevation relative to time of insemination in dairy cows. J. Dairy Sci. 94:4538-4545. https://doi.org/10.3168/jds.2011-4293.

Leach, K. A., H. R. Whay, C. M. Maggs, Z. E. Barker, E. S. Paul, A K. Bell, and D. C. J. Main. 2010. Working towards a reduction in cattle lameness: 2. Understanding dairy farmers' motivations. Res. Vet. Sci. 89:318-323. https://doi.org/10.1016/j.rvsc.2010.02.017.

McDougall, S., E. Abbeloos, S. Piepers, A. S. Rao, S. Astiz, T. van Werven, J. Statham, and N. Pérez-Villalobos. 2016. Addition of meloxicam to the treatment of clinical mastitis improves sub- 
sequent reproductive performance. J. Dairy Sci. 99:2026-2042. https://doi.org/10.3168/jds.2015-9615.

McDougall, S., M. A. Bryan, and R. M. Tiddy. 2009. Effect of treatment with the nonsteroidal antiinflammatory meloxicam on milk production, somatic cell count, probability of re-treatment, and culling of dairy cows with mild clinical mastitis. J. Dairy Sci. 92:4421-4431. https://doi.org/10.3168/jds.2009-2284.

McDougall, S., F. Rhodes, and G. Verkerk. 2005. Pregnancy loss in dairy cattle in the Waikato region of New Zealand. N. Z. Vet. J. 53:279-287. https://doi.org/10.1080/00480169.2005.36561.

Rutten, C. J., W. Steeneveld, C. Inchaisri, and H. Hogeveen. 2014. An ex ante analysis on the use of activity meters for automated estrus detection: To invest or not to invest? J. Dairy Sci. 97:6869-6887. https://doi.org/10.3168/jds.2014-7948.

Santos, J. E. P., R. L. A. Cerri, M. A. Ballou, G. E. Higginbotham, and J. H. Kirk. 2004. Effect of timing of first clinical mastitis occurrence on lactational and reproductive performance of Holstein dairy cows. Anim. Reprod. Sci. 80:31-45. https://doi.org/10.1016/ S0378-4320(03)00133-7.

Schrick, F. N., M. E. Hockett, A. M. Saxton, M. J. Lewis, H. H. Dowlen, and S. P. Oliver. 2001. Influence of subclinical mastitis during early lactation on reproductive parameters. J. Dairy Sci. 84:1407-1412. https://doi.org/10.3168/jds.S0022-0302(01)70172 -5 .

Sørensen, J. T. 1990. Validation of livestock herd simulation models: A review. Livest. Prod. Sci. 26:79-90. https://doi.org/10.1016/0301 -6226(90)90058-E
Swinkels, J. M., A. Hilkens, V. Zoche-Golob, V. Krömker, M. Buddiger, J. Jansen, and T. J. G. M. Lam. 2015. Social influences on the duration of antibiotic treatment of clinical mastitis in dairy cows. J. Dairy Sci. 98:2369-2380. https://doi.org/10.3168/jds.2014 -8488 .

Valeeva, N. I., T. J. G. M. Lam, and H. Hogeveen. 2007. Motivation of dairy farmers to improve mastitis management. J. Dairy Sci. 90:4466-4477. https://doi.org/10.3168/jds.2007-0095.

Van Es, A. J. H. 1978. Feed evaluation for ruminants. I. The systems in use from May 1977-onwards in The Netherlands. Livest. Prod. Sci. 5:331-345. https://doi.org/10.1016/0301-6226(78)90029-5.

Vermeij, I. 2012. KWIN Handboek Kwantitatieve Informatie Veehouderij 2012-2013 [Manual Quantitative Information Livestock Farming 2012-2013]. Livestock Research, Wageningen UR, Lelystad, the Netherlands.

Wood, P. D. P. 1967. Algebraic model of the lactation curve in cattle. Nature 216:164-165. https://doi.org/10.1038/216164a0.

Zwald, N. R., K. A. Weigel, Y. M. Chang, R. D. Welper, and J. S. Clay. 2004. Genetic selection for health traits using producerrecorded data. I. Incidence rates, heritability estimates, and sire breeding values. J. Dairy Sci. 87:4287-4294. https://doi.org/10 .3168/jds.S0022-0302(04)73573-0. 